\title{
DEVELOPMENTS IN METEOROLOGY
}

\author{
CENTENARY CELEBRATIONS OF THE ROYAL METEOROLOGICAL SOCIETY
}

HE celebrations of the centenary of the Royal
Meteorological Society were held, partly in
Oxford and partly in London, during the period
March 28-April 3, 1950. The centenary meeting of
the Society was held in the Society's House at 49
Cromwell Road, South Kensington, on April 3, that
day being the actual anniversary of the foundation
(see Nature, March 25; p. 463). At this meeting the
president, Sir Robert Watson-Watt, read the loyal
message sent to the Society's patron, H.M. the King,
and the gracious reply which His Majesty had sent
to the Society. A large number of congratulatory
letters received from learned societies in Britain and
abroad were read, and the president announced the
election, as honorary fellows, of the following eminent
meteorologists from overseas : S. K. Banerji (India);
R. Bureau (France); H. Ficker (Austria); F. A. Vening
Meinesz (Holland); and F. W. Reichelderfer (U.S.A.).
After the presentation of the Buchan and Darton
Prizes, the newly founded Hugh Robert Mill Prize
was awarded to Dr. Hugh Robert Mill himself; but
Dr. Mill died on May 5 before the prize could be
conveyed to him. Prof. Vening Meinesz then delivered
a centenary address, on the value of meteorology to
the community. The considerable attendance from
abroad at this meeting, and the warmth of the
greetings received from learned societies both at home
and abroad, were a source of pride and satisfaction
to officers and fellows of the Royal Meteorological
Society.
The

The days preceding the day of the centenary meeting had been devoted to meetings and discussions, the start being made at Oxford on March 28, with a series of symposia which continued up to midday on March 30. Saturday, March 31, was spent in visiting the Meteorological Office, Harrow, in the afternoon, followed in the evening by a conversazione in the Society's rooms, at 49 Cromwell Road, South Kensington. The morning of April 3 was devoted to a visit to the Department of Meteorology, Imperial College of Science and Technology, a large part of the time being devoted to a discussion on atmospheric turbulence. On the evening of the same day was held the final event of the celebrations, a dinner which was very well attended, and was an extremely happy event.

It would be pleasant to record that the symposia had led to an immediate solution of some of the outstanding problems of meteorology; but this we cannot truthfully do. The discussions, which ranged over a wide field of meteorology, will be reproduced in full in a special number of the Quarterly Journal to be published during the summer of 1950 , and all we shall attempt to do here is present a brief account of those new ideas, put forward in the course of the discussions, which may be of general interest.

In the first symposium, on "Radiation and its Effect on the Troposphere and Lower Stratosphere", Prof. A. Adel, of Arizona State College, described an experimental investigation of the polyatomic radiating and absorbing constituents of the atmosphere. In addition to water vapour, carbon dioxide and ozone, he found that nitrous oxide and methane showed marked radiation and absorption. The computed effective radiating temperature for ozone was found to vary from $-35^{\circ}$ to $-45^{\circ} \mathrm{C}$., while that for nitrous oxide had values between $0^{\circ}$ and $10^{\circ} \mathrm{C}$. showing that while the ozone is mainly at high levels, the nitrous oxide is mainly limited to low levels in the atmosphere. R. M. Goody, of Cambridge, described spectroscopic observations made in aircraft at $30,000 \mathrm{ft}$., which indicated a total water-vapour content of the air above that level equivalent to about $5 \times 10^{-3} \mathrm{gm} . / \mathrm{cm} .{ }^{2}$. Some of Goody's spectral records extended as far as $7 \mu$.

The second symposium, that on "The Physics of Cloud and Precipitation", was perhaps the most interesting of all. Prof. G. M. B. Dobson, of Oxford, in his introduction, stated that recent investigations have shown that at temperatures down to $-15^{\circ} \mathrm{C}$. clouds usually consist of supercooled water, while below $-41^{\circ} \mathrm{C}$. they consist of ice particles, with an intermediate zone of temperatures in which some doubt remains as to what occurs.

Dr. V. J. Schaefer, of the G.E.C. Laboratory, U.S.A., showed a remarkable set of slides illustrating the effects of seeding clouds with solid carbon dioxide or silver iodide. The effect of over-seeding was unexpectedly found to be to inhibit the growth of cloud. The ice crystals formed in a cold chamber were shown to be similar to those taken from natural clouds. B. J. Mason (Imperial College) showed that while existing theories of the growth of crystals give an impossibly slow rate of growth, the application of Frank's dislocation theory gives a satisfactory rate of growth of the crystal in terms of the molecular properties of the crystal and the ambient conditions. $\mathrm{He}$ was also able to explain how various ice crystal forms can arise in different types of cloud, dealing especially with the transition from polyhedral to dendritic growth. C. Lafargue (France) described how he found that drops of water or aqueous solutions, suspended on spider threads in air or in oil, froze at a temperature of $-40 \cdot 5^{\circ} \pm 1 \cdot 5^{\circ} \mathrm{C}$. when the diameter of the drops did not exceed $20 \mu$. For large drops the freezing point varied with size and concentration. A. W. Brewer and H. P. Palmer (Oxford) described laboratory studies of the Findeisen ice-splintering process. They found that small splinters of ice are formed when impure water freezes, and when hoarfrost grows. These splinters are probably of great importance in providing nuclei of further ice crystals in a cloud. These observations, taken in conjunction with Mason's application of Frank's theory to the growth of crystals, appear to throw light on the difficulty which has been experienced in finding the nature of the sublimation nuclei in the atmosphere, and the rapidity of the growth of condensation once it has started.

In the symposium on "The Structure of Weather Systems", two widely different views were put forward, Dr. Bleeker (Holland) emphasizing the effect of local heating or cooling of air masses by land and sea, and Prof. C. G. Rossby (Chicago and Stockholm) suggesting that the dynamics of depressions could be largely understood without any consideration of the heat supply.

The same diverging views were advanced in the symposium on "The General Circulation of the Atmosphere". Prof. S. Petterssen (U.S.A.) outlined a theory of the maintenance of the general circulation by vorticity transfer. Dr. E. T. Eady (Imperial 
College) showed that the instability of baroclinic motion leads to a continual development of 'eddies', that is, of cyclones and anticyclones, associated with poleward and upward transfer of heat from low levels in low latitudes to high levels in the polar regions, a fundamental result of considerable importance. He also advanced a tentative explanation of the observed eddy-transport of angular momentum.

In the symposium on "Climatic Changes", Prof. K. Faegri (Bergen) pointed out the complexity of palæoclimatological evidence, the growth of trees depending on rainfall minus evaporation. He added that, while long-period variations tend to be widespread, the variations of shorter period are in genera] localized. $\mathrm{He}$ considered that the changes shown in the climate of north-western Europe since the last ice age are also shown in the climates of all other regions, in both northern and southern hemispheres. Confirmatory evidence of this was given by several other speakers.

The symposium on "Meteorology and the Community" was opened by Sir Nelson Johnson, director of the Meteorological Office, London, who described the services rendered by the Meteorological Office to a wide range of interests. Sir David Brunt, Imperial College, atter outlining some of the ways in which meteorology can help the engineer with forecasts of various kinds, suggested that there are in engineering, and in many other technologies, problems in which the meteorologist can help by applying meteorological methods to their discussion. Such services could be rendered by the individual without the backing of a large organisation. He also pleaded for a thorough survey of river flow in the British Isles. Sir William Gammie Ogg described the repercussions of meteor. ology on agriculture. He spoke of the effects of excessive rainfall on various types of soil and on the formation of soil, and referred to the effect of weather conditions on the incidence and spread of plant diseases. Other speakers agreed in finding varied interests in which meteorology can help, while N. R. Hagen (U.S.A.) thought that the private consulting meteorologist could perform a useful function.

The discussion on "Atmospheric Turbulence" was opened by Prof. P. A. Sheppard (Imperial College), who directed attention to the difficulty of defining the time-interval over which the mean value of $a$ varying quantity should be taken, and described a new instrumental method of measuring the diffusion of momentum and heat in the atmosphere. He gave a brief account of the measurements of the fluctua. tions of temperature and humidity in the lowest 10 metres over Lough Neagh, Northern Ireland, during April 1949. He was followed by H. Charnock, who elaborated the question of defining the mean value, and showed other results derived from the Lough Neagh observations. These two speakers indicated a new method of approach to the problem of diffusion by turbulence, namely, that of using specially designed instruments to obtain direct measurements of products of the momentary variations of temperature and other meteorological factors, combining these with an integrating mechanism which will yield arithmetical values for the diffusion of various entities. This indicates the possibility of a considerable advance on the days when discussion of turbulence involved the assumption of a coefficient of eddy diffusivity varying with height in accordance with some simple mathematical relation.

There was general agreement among those who attended the centenary celebrations that the symposia had been of great value in bringing out the widely differing lines of attack on the problems of meteor. ology which are being followed. It was evident that there is at the present time far greater activity in meteorological research than at any time in the past, and that while final solutions of the problems reviewed were not attained, there was evidence of definite advance in some of the most difficult problems of meteorology.

D. BRUNT

\section{METABOLIC INTERRELATIONS}

A CONTINUATION of the reports of the Con. ferences on Metabolic Aspects of Convalescence, sponsored by the Josiah Macy, Jr. Foundation, New York, has been published in a volume entitled "Metabolic Interrelations"*. The former Conferences originated as "a joint effort to do something useful for the armed services"; they have continued with a gradual swing of interest away from immediate clinical preoccupations towards more academic problems, and this swing is recognized in the change of title.

Although the statement that "Today, to be effective, medical research and practice must embrace data from all the disciplines embracing nuclear physics at one end of the spectrum and cultural anthropology at the other" and the oft-voiced plea for inter-disciplinary co-operation are entirely praiseworthy, it may be questioned whether the publication of more or less verbatim reports of impromptu discussions on ordinary papers is of much value. Re-circulation of papers and careful editing of discussions, allowing second thoughts, may indeed lead to a useful product; but questions, referring to details of technique, which could have been eliminated by more careful preparation of papers, and unanswered questions (one series ends plaintively, "What is the adrenal $N$ hormone?") serve to exasperate rather than to enlighten the reader. One feels that such discussions were probably of great value to the participants, and that such conferences do indeed further co-operation, particularly of those vitally interested in this field; but revision and publication through existing journals would be of more use to the scientific community than presentation in this semi-digested state.

The nineteen papers presented comprise seven on various aspects of bone and cartilage metabolism, one study on carbon-14 distribution after its continuous administration, two on gastric secretion, two on isotopic studies of intermediary metabolism, six on steroid metabolism (including two clinical papers on adrenocorticotrophin) and a speculative paper on intracellular energy transfer. A good deal of the material has been published elsewhere.

In the field of bone and cartilage metabolism, A. B. Gutman and T. F. Yü show that in vitro calcification of epiphysis slices is inhibited by inhibitors of glycolysis and phosphorylation when the substrate is a solution of calcium phosphate, and that the inhibition is at least partly reversed by adding glucose-1-phosphate, fructose-1,6-diphosphate or 3-phosphoglycerate. Phosphate was rapidly split from adenosinetriphosphate, but no calcification resulted.

* Metabolic Interrelations. Transactions of the First Conference, New York, February 7-8, 1949 . Edited by Dr. Edward C. Reifenstein, jun. Pp. 193. (New York: Josiah Macy, Jr. Foundation, 